\title{
The Complications of Trabeculectomy (A 20-Year Follow-up)
}

\author{
P. G. WATSON, C. JAKEMAN, M. OZTURK, M. F. BARNETT, F. BARNETT, \\ K. T. KHAW \\ Cambridge
}

\begin{abstract}
Summary
The complications of trabeculectomy were studied in two groups of patients taken from a stable white population. The first group who had had their operation when it was first introduced 22 years ago, had been previously treated with prolonged medication, the second group had been operated upon recently and had had short-term pre-operative medication. This study confirmed that trabeculectomy predictably reduces the intraocular pressure to within the accepted normal range and that the pressure level below which the intraocular pressure could not be expected to fall was $\bumpeq 14 \mathrm{~mm} / \mathrm{Hg}$. It also revealed that although some post operative abnormality was noted in two-thirds of the patients there were no long term problems which could be related to any operative or immediately post-operative complications, including shallow anterior chambers, uveitis and hyphaema. However, there was a long term reduction in the visual acuity and visual fields of about one-third of the patients, which was not related to cataract formation, macular problems, the height of the preoperative intraocular pressure, the amount by which this fell as a result of the surgery, or the amount, length or type of preoperative medication given before the operation. Although there was some increase in cataracts throughout the whole long term group this was mainly in those who had cataract prior to surgery; the increase was not related to operations or any other factor other than corneo-lenticular contact post-operatively.
\end{abstract}

Trabeculectomy was first introduced in $1967^{1,2}$ in an attempt to reduce the incidence of flat or very shallow anterior chambers which followed operations in which the full thickness of the sclera was removed such as the Elliott trephine operation and to a lesser extent posterior lip sclerectomy and the Scheie procedure. Other operations such as Iris Inclusion and the Stallard operation were complicated to perform and had proved to be unsatisfactory because of a high incidence of uveitis and occasionally sympathetic ophthalmia. Trabeculectomy (in which these complications are unusual) has become the accepted method of surgical treatment of open angle glaucoma in the elderly. ${ }^{3-16}$ It is usually performed as a first procedure in all forms of complicated glaucomas but it is known to fail in young eyes, ${ }^{17}$ in those who produce large amounts of fibrous tissues "which prevents the subconjunctival drainage of fluid, ${ }^{18-21}$ and in eyes rendered aphakic by intracapsular cataract extraction. ${ }^{22}$ It is inevitable that with such widespread use many and varied complications will be reported (Table I).

The purpose of this investigation was to examine the complications of trabeculectomy in two groups of patients: those who had had long term medical therapy for glaucoma prior to surgery, and those who had had trabeculec- 
Table I Reported complications of trabeculectomy

Absent Anterior Chambers with Corneal Touch Shallow Anterior Chambers with or without Choroidal Detachments

Hypotony

Uveal Effusion

Supra-Choroidal Haemorrhage

Ciliary Body Incarceration

Staphyloma

Lens Induced Uveitis

Late Onset of Cataract

Reduction in Visual Field

Sudden Loss of Vision

Endophthalmitis

tomy shortly after diagnosis of glaucoma; we also wanted to determine if there were any factors related to surgery that were associated with long term visual deterioration.

\section{Methods}

Two distinct groups of patients were identified. The case notes were reviewed of the first 200 patients ( 387 eyes) who had had trabeculectomy for glaucoma at Addenbrooke's Hospital, Cambridge. The first of these operations was performed in May 1967, the latest January 1973. These patients were drawn from the population of Cambridge and its surrounding areas. They were almost exclusively white and tended to remain in the same area throughout their lives. They were followed for the 22 years or until they died and were used to examine the long term outcome following surgery particularly with regard to any change which might have been continuous over the prolonged follow up (average 110

Table II Types of Glaucoma Treated by Trabeculectomy

\begin{tabular}{|c|c|c|c|c|c|}
\hline \multicolumn{6}{|c|}{ Follow Up } \\
\hline \multicolumn{2}{|c|}{$\begin{array}{lc} & \text { Long Term Study } \\
& 150 \text { eyes } \\
\text { Average } & 110 \text { months } \\
\text { range } & 12-240 \text { months }\end{array}$} & $\begin{array}{c}\text { Average } \\
\text { range }\end{array}$ & \multicolumn{3}{|c|}{$\begin{array}{c}\text { Short Term Study } \\
89 \text { eyes } \\
20 \text { months } \\
4-42 \text { months }\end{array}$} \\
\hline \multirow[t]{2}{*}{ Study } & \multicolumn{3}{|c|}{ Long Term Study } & \multicolumn{2}{|c|}{ Short Term } \\
\hline & & Eyes & $\%$ & Eyes & $\%$ \\
\hline \multicolumn{2}{|c|}{ Open Angle } & 18 & 78 & 67 & 75 \\
\hline \multicolumn{2}{|c|}{ Chronic Closed Angle } & 17 & 11 & 15 & 17 \\
\hline \multicolumn{2}{|c|}{ Secondary } & 9 & 6 & 7 & 8 \\
\hline \multicolumn{2}{|c|}{ Congenital } & 4 & 2 & 0 & 0 \\
\hline \multicolumn{2}{|l|}{ Other } & 2 & 1 & 0 & 0 \\
\hline
\end{tabular}

months, range $12-240$ months). The group was also examined to determine whether minor complications at surgery or shortly after had any long term effect on the final result.

The second group consisted of 92 patients (112 eyes) (average follow up 20 months, range 4-42 months) being those patients who had undergone trabeculectomy between January 1985 and December 1988. This group who had not had a prolonged period of ocular medication before surgery was used as a comparison for examining differences in the short term outcome of surgery (Table II).

Preoperative data on visual status immediately before the trabeculectomy, the type of surgical procedures performed, the pre-, periand post-operative care and events, together with the latest follow up data on visual acuity, visual fields and presence, or absence of cataract were obtained from patient records.

\section{Visual Acuity}

Visual acuity was measured at $6 \mathrm{~m}$ on illuminated Snellen type. The acuity was measured and recorded at the same site throughout the study. A change of visual acuity by one line was classified as one grade better or worse, two lines two grades, three or more as three grades.

\section{Optic disc assessment}

The optic disc was assessed by many different doctors each giving their interpretation of the cup/disc ratio which was recorded. Photographic records were not used therefore no detailed examination of the optic disc changes was undertaken.

\section{Visual Fields}

The visual fields of the early (1967-1973)

Table III Age at the Time of Operation (Both Groups)

\begin{tabular}{ccc}
\hline Age & $\%$ & Eyes \\
$<50$ & 11.3 & 17 \\
$50-59$ & 9.3 & 14 \\
$60-69$ & 38.0 & 57 \\
$70-79$ & 31.3 & 47 \\
$80+$ & 10.0 & 15 \\
$93(62 \%)$ Male & & $57(38 \%)$ Female \\
& \\
Family History of Glaucoma & $27 \%$ \\
History of Vascular Disease & $15 \%$ \\
Diabetes & $9 \%$ \\
\hline
\end{tabular}


Table IV Bleb Formation

\begin{tabular}{lrc}
\hline $\begin{array}{l}\text { Early Study } \\
\text { Final follow up }\end{array}$ & $\mathrm{n}$ & Mean IOP \\
\hline No bleb & 3 & $17.0(4.6)$ \\
Flat & 3 & $21.3(6.7)$ \\
Shallow & 4 & $16.8(4.8)$ \\
Good & 117 & $15.7(4.3)$ \\
Cystic & 7 & $14.3(4.2)$ \\
Not stated & 14 & $20.1(3.3)$ \\
& & \\
Recent Study & & \\
Final follow up & $\mathrm{n}$ & Mean IOP \\
\hline No & 1 & $42.0(-)$ \\
Shallow & 9 & $13.1(6.0)$ \\
Good & 72 & $14.9(4.2)$ \\
Cystic & 7 & $13.6(3.4)$ \\
\hline
\end{tabular}

group were assessed on the Bjerrum screen at 2 metres distance using $5 \mathrm{~mm}$ and $2 \mathrm{~mm}$ test targets. The field assessments were undertaken by experienced technicians. The visual fields in the recent series (1985-1988) were assessed on the Humphrey visual field analyser or the Dicon visual field analyser. The same apparatus was used by each patient. The fields were graded as in Table VI.

\section{Cataract}

Cataract was assessed objectively by observation of the red reflex on a dilated pupil and on the slit lamp. They were graded as slight, if peripheral, or with a very slight central distortion. Moderate if the opacity was in the visual axis (thus all posterior subcapsular cataracts were regarded as moderate) and severe if sufficient to interrupt and diminish the red reflex.

All data were coded, entered on computer at the University of Cambridge and analysed using the Statistical Package for the Social Sciences (SPSSX). Only those subjects who had adequate baseline and follow up data were used for analysis. The baseline and follow up distribution of variables, and the effects of possible factors which might be associated with visual outcome and changes, in particular, surgical complications, were examined.

For the early (1967-1973) study, adequate follow up data on the outcome and course of the disease were available on 94 patients (150 eyes). Of these 27 persons (45 eyes) died during the course of follow up; $76 \%$ of eyes were followed at least five years, $49 \%$ followed at least 10 years, and $22 \%$ followed over 15 years. The loss to follow up through deaths was compatible with the older age group and length of follow up (Tables II, III).

For the recent (1985-1988) study, there were adequate data for 83 patients ( 89 eyes), with a mean follow up time of 20 months.

\section{Trabeculectomy}

The technique of trabeculectomy used was varied only in that in the later cases in both series a fornix based conjunctival flap was fashioned rather than the limbus based flap originally used. This did not make any difference to the results either from the point of visual acuity, intraocular pressure or from complications. Although post-operative leakage from the flap was recorded in $15 \%$ of the patient with fornix based flap the rate of shallow anterior chamber was the same and there was no increase in long term complications.

A $4 \times 4 \mathrm{~mm}$ superficial flap was dissected forwards to the limbus and then depending on which surgeon performed the operation the flap of deep sclera was dissected forwards from behind to include the scleral spur (PGW) or dissected backwards from the limbus to, but not including the scleral spur (JEC). Again the difference in technique made no difference to the results. The operations were performed by consultant surgeons or by resident staff under supervision. There was no difference in the results between surgeons.

\section{Results}

\section{Intraocular Pressure}

The data from both of these studies were compared. When the regression analysis of the preoperative intraocular pressure was compared with the fall of intraocular pressure achieved by operation it was found in both the 1967-1973 series and the 1985-1988 series that the intraocular pressure was predictably reduced by trabeculectomy, the higher the intraocular pressure the greater the fall. Ninety per cent had a final IOP of $<20 \mathrm{mmHG}$ in both series. Only three eyes whose initial IOP was greater than $20 \mathrm{mmHg}$ showed no fall of pressure. In five eyes whose 
IOP was initially less than $20 \mathrm{mmHG}$ the IOP rose. The pressure at which no response could be expected from trabeculectomy, the zero pressure change from operation was $\bumpeq$ $14 \mathrm{mmHg}$; the episcleral tissue pressure. The drop in the intraocular pressure between the first pre-operative level and the last follow up in the early study was 0.97 per unit of baseline IOP and 0.99 per unit of baseline IOP for the recent study; virtually $1: 1$ and the same for each series (Figs $1,2,3$ ). In the early study only one person out of 150 was taking medication at the final follow up; exclusion of that one person does not make any material difference to the plot of change of IOP with baseline IOP. In the recent study, nine out of 89 patients were taking medication at final follow up:

As would be expected the nine taking medication had higher baseline IOPs, with higher follow up IOPs. If medication users are excluded from the figures, the slope is slightly steeper but not significantly non materially so (still approximately 1:1).

These results are identical to those pre- viously reported and the scatter is the same..$^{3,6}$ There is no long term rise of intraocular pressure in any group with time. The slope immediately (one week) post operatively is slightly less 0.7912 , the pressure in some eyes with high pressure preoperatively not having fallen to their final level at this stage (Fig. 1). The slope at the intermediate follow up is almost the same as the final follow up (0.862). It is considered therefore that the data in the previously recorded series and the current studies are comparable.

\section{Bleb Formation}

Subconjunctival drainage of aqueous is indicated by bleb formation. Whilst 'good' bleb was apparent in over $80 \%$ the absence of a bleb was not equated with failure to reduce the intraocular pressure (Table IV).

\section{Short Term Complications}

Some minor complications thought worthy of recording in the notes, eg cells in the $\mathrm{AC}$, small hyphaema, slight shallow AC, occurred in $54 \%$ of all the patients in this series (Fig. 4).

\section{Fall of I.O.P First Post- Operative Visit}

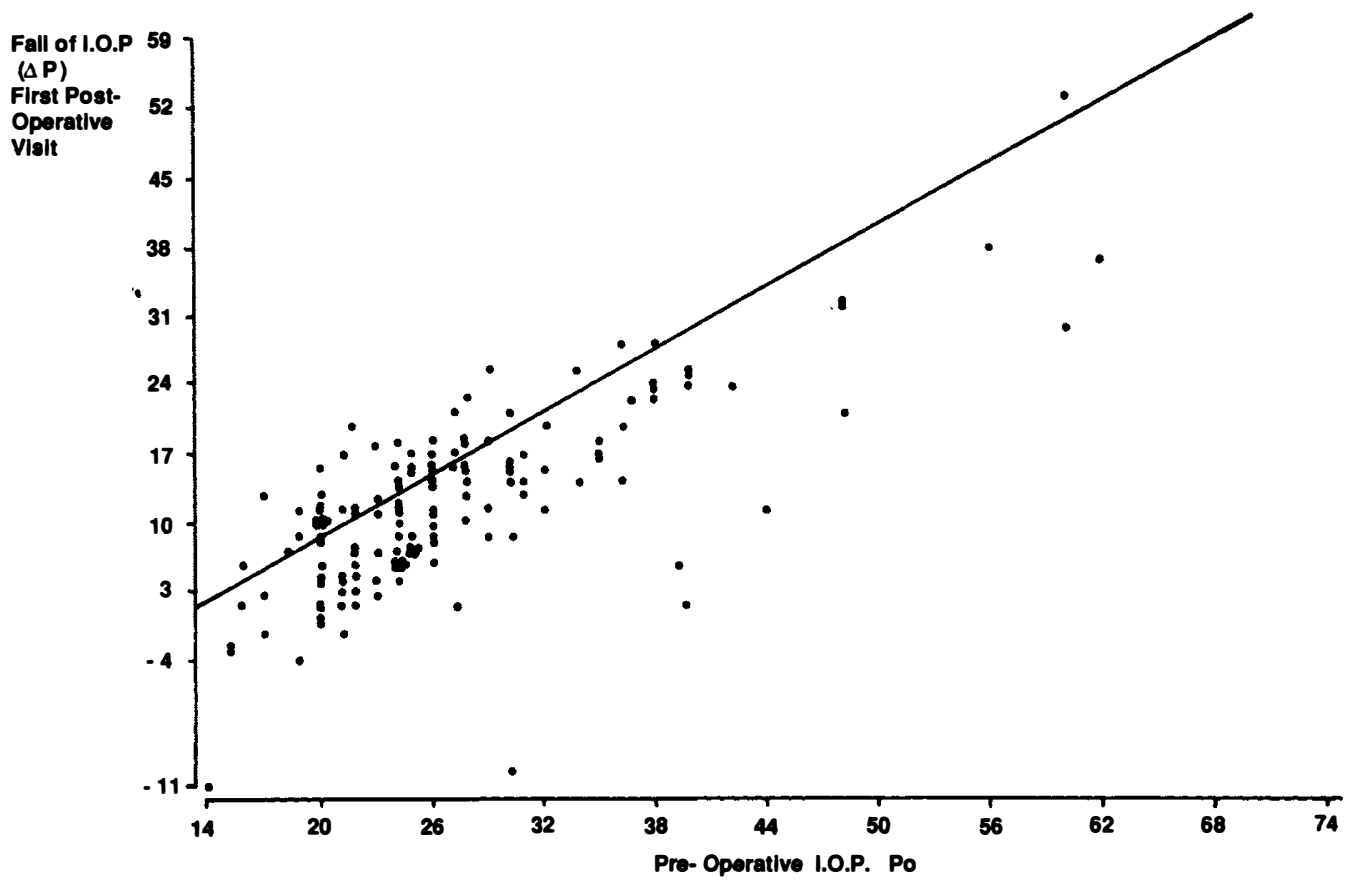

Fig. 1 Regression analysis of preoperative intraocular pressure against the fall of intraocular pressure achieved by trabeculectomy of 150 eyes at the first postoperative clinic visit in the early 1967-1973 study. 


\section{Fall of I.O.P Final Follow up}

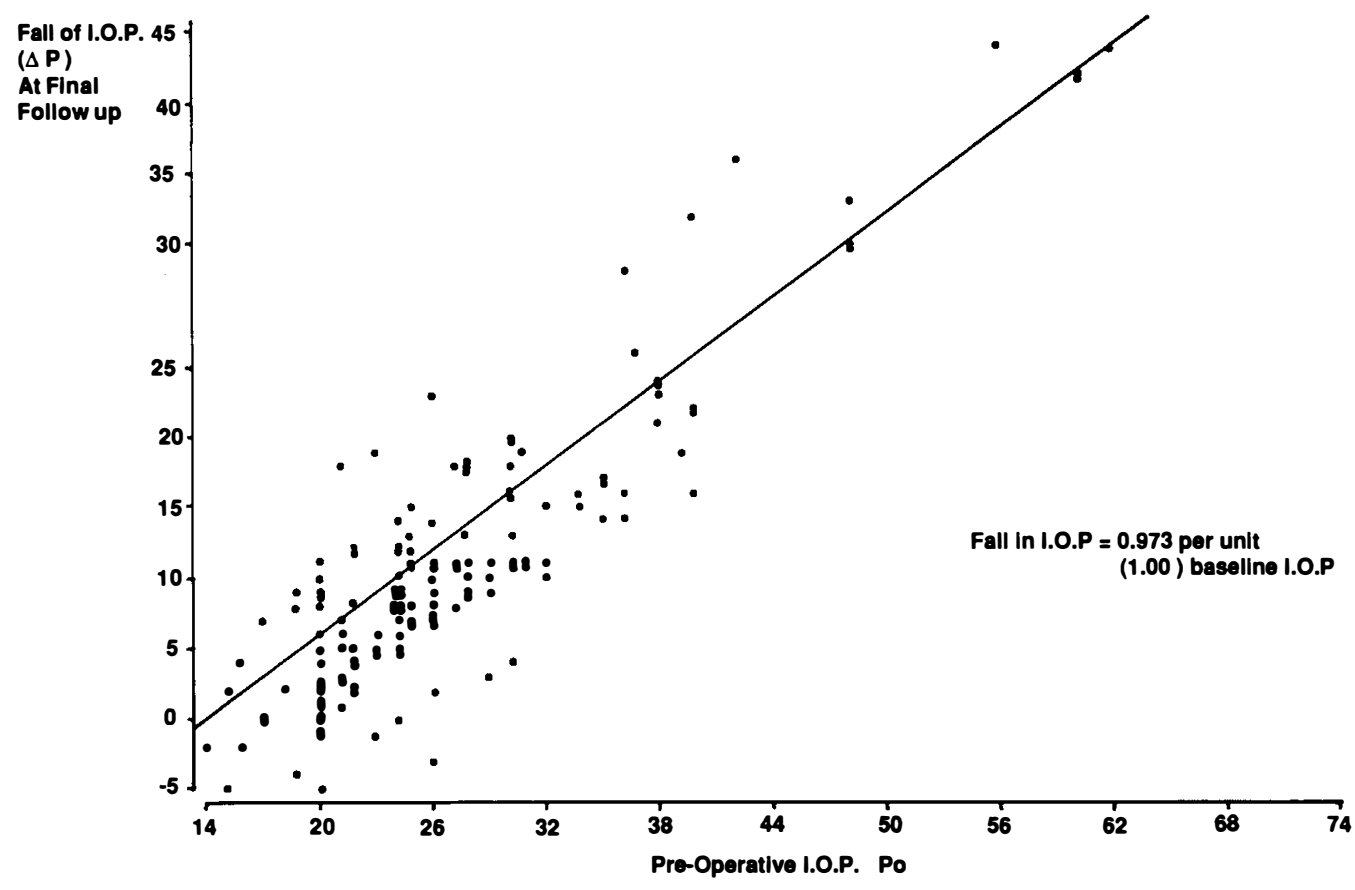

Fig. 2 Regression analysis of the preoperative intraocularpressureagainst the fall in intraocularpressure achieved by trabeculectomy of 150 eyes at the final follow up in the early (1967-1973) study.

Although the records were made by different observers it is unlikely that there has been any change in the methods of observation or the way these have been recorded over the years. The results were therefore analysed to ascertain whether these complications had any effect on the visual acuity, the visual fields, the formation of cataract, the state of the drainage bleb or the production of synechiae both in the short and the long term.

\section{Hyphaema and Uveitis}

Synechiae formation was induced in 16 eyes by a mild uveitis and by hyphaemata which lasted more than three days but no other change in the eye could be detected as a result of these minor complications in particular no relationship could be found to the late formation of cataract even in patients who had quite severe uveitis post operatively.

\section{Shallow Anterior Chamber}

The anterior chamber (AC) was reported to be shallow in $16 \%$ of the early series and $28 \%$ of the recent series. A shallow anterior cham- ber has been regarded as an eye in which there was irido corneal contact but in which there is no contact between the lens and the cornea. (If such contact exists these have been called a flat AC). Shallow AC may or may not be accompanied by choroidal detachments but the presence or absence of detectable choroidal detachment did not affect the results). No relationship could be detected between shallow AC and failure of the control of IOP, reduction in visual acuity or visual field and no relationship could be detected between this complication and the development of cataract at any stage.

\section{Flat Anterior Chamber}

Flat anterior chambers were recorded in six eyes. Two of these required cataract extraction, one other had a permanent reduction of visual acuity from $6 / 6$ to $6 / 60$ and had a reduction of visual field.

\section{Other complications at or immediately after surgery}

Of the complications listed in Table I supra 


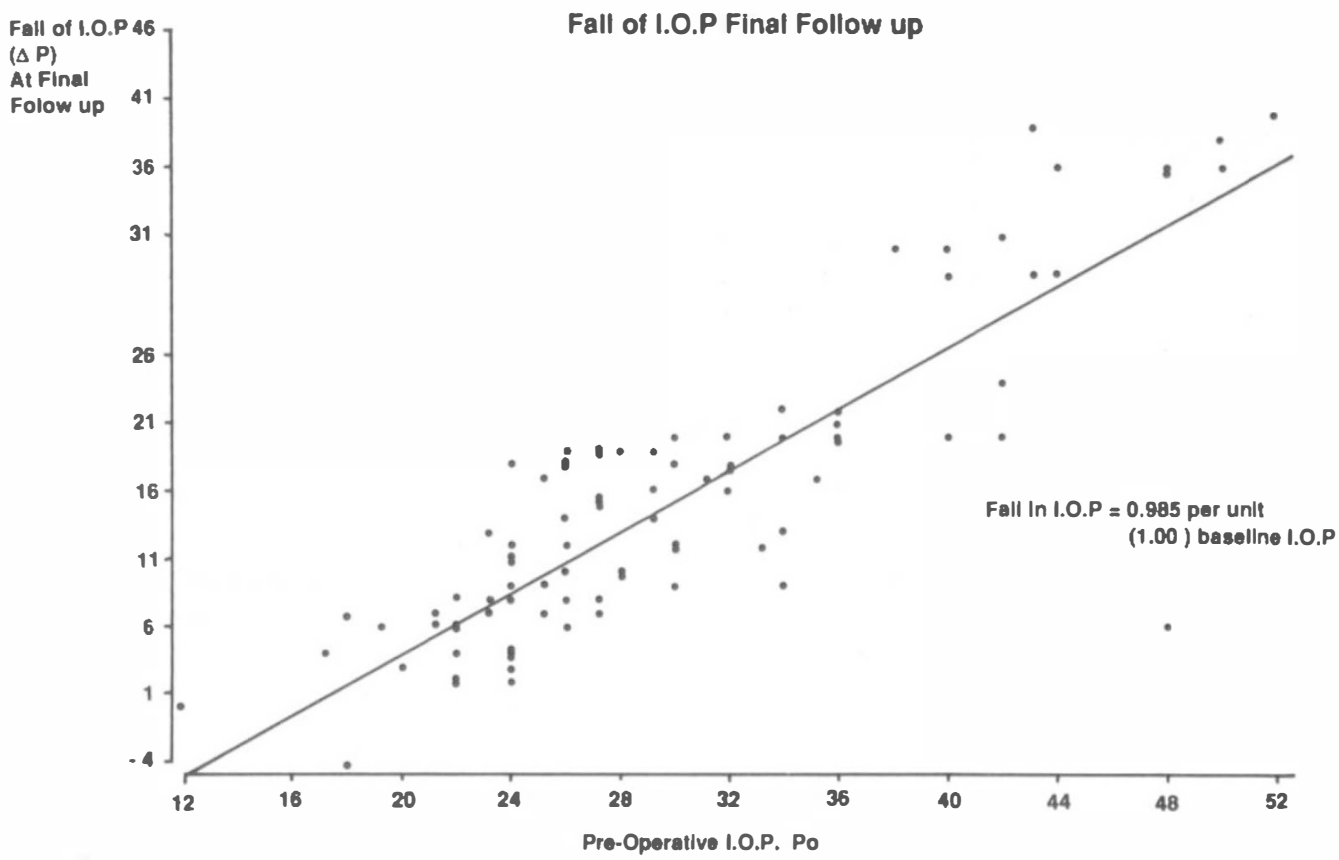

Fig. 3 Regression analysis of intraocular pressure of preoperative intraocular pressure against fall of intraocular pressure achieved by trabeculectomy of 89 eyes at the final follow up in the recent 1985-1988 study.

choroidal haemorrhage occurred in two patients at the time of surgery. Neither was large and the final visual acuity was good. Sudden loss of vision, ciliary body incarceration has not been observed. Neither uveal effusion or staphyloma formation were seen in any patients, nor did any have any endophthalmitis or infected cystic blebs.

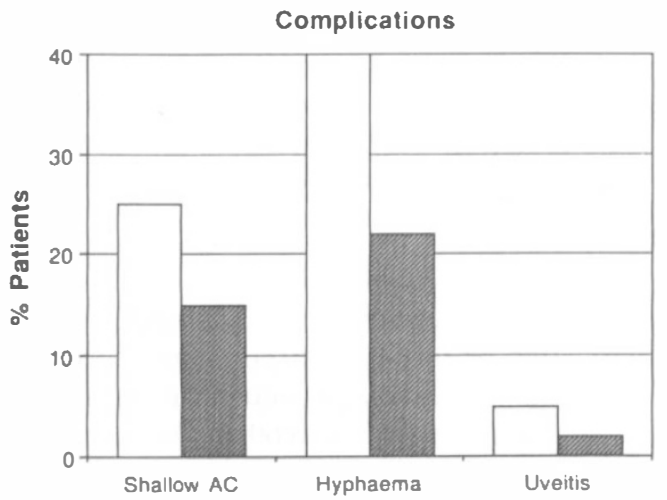

Fig. 4 The incidence of hyphaema, shallow anterior chambers and uveitis in both series. (239 eyes) (Plain recent series, Hatched early series).
Hypotony

Seven patients $(5 \%)$ in the early study and 22 $(25 \%)$ in the recent study had IOPs of $5 \mathrm{mmHg}$ or less in the immediate post operative period but only three $(2 \%)$ patients in the early study and one $(1 \%)$ patient in the recent study retained this very low level throughout the duration of the follow up. Two

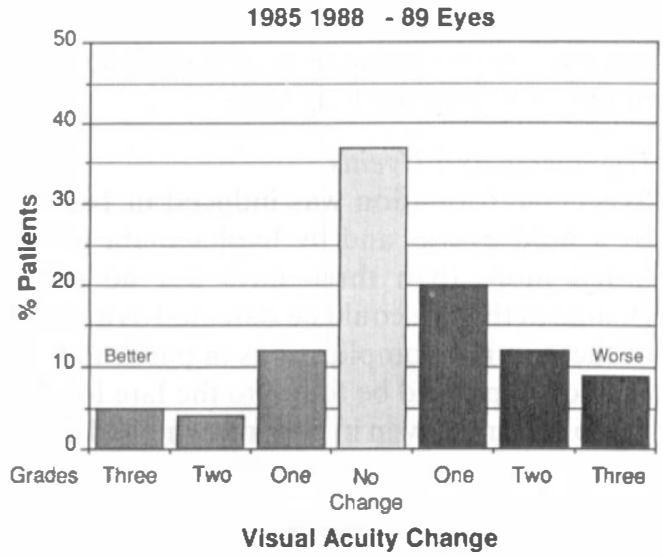

Fig. 5 The improvement or deterioration of visual acuity before operation compared with that at the final follow up in the recent study (89 eyes). 


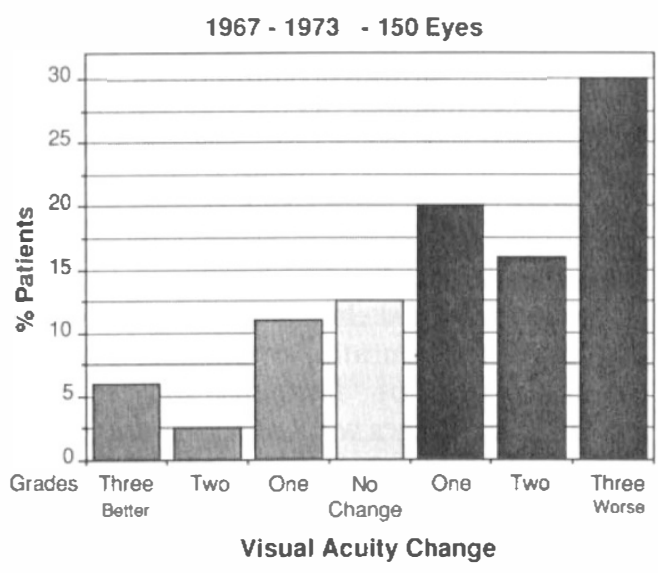

Fig. 6 The improvement or deterioration of visual acuity before operation compared with at the final follow up in the early term study (150 eyes).

of these eyes developed cataract during the period of follow up but otherwise all retained their pre-operative acuity and visual field.

\section{Visual Acuity}

One of the major differences between the recent and the early studies was the reduction of the visual acuity with time (Figs. 5, 6).
Change in acuity was analysed in detail. Naturally the 20 eyes which developed cataract accounted for a large amount of this change. If those with cataract or obvious macular degeneration are removed from the calculation there is still a reduction in the visual acuity which was related directly to the rate of the visual field loss but it was not related to the initial intraocular pressure, the amount of fall in IOP, the type of glaucoma or bleb, any post operative complications or the presence of IOP less than $5 \mathrm{mmHg}$ over a long period. A quarter of visual loss occurred during the first year with most of this shortly after surgery (Figs 5, 6).

\section{Cataract}

Assessment of increasing cataract was objective because not all those whose cataract increased suffered visual acuity loss; nor did all those with visual acuity loss have cataract.

Ten out of the 150 eyes in the early study had had a cataract removed before trabeculectomy. Of the remainder, cataract increased in 20 of 140 eyes $(14.2 \%)$ during the early study; of these, eight $(5.7 \%)$ required remo-

Table V Progression of Cataract

\begin{tabular}{|c|c|c|c|c|c|}
\hline \multicolumn{6}{|c|}{ Early Study } \\
\hline $\begin{array}{l}\text { Cataract } \\
\text { at final } \\
\text { follow up }\end{array}$ & $\begin{array}{l}\text { Not stated } \\
\text { Removed before } \\
\text { trabeculectomy } \\
\text { No change } \\
\text { Worse } \\
\text { Worse, requiring } \\
\text { surgery }\end{array}$ & $\begin{array}{r}0 \\
89 \\
3\end{array}$ & $\begin{array}{r}0 \\
12 \\
9 \\
3\end{array}$ & $\begin{array}{r}10 \\
0 \\
0 \\
\\
0\end{array}$ & $\begin{array}{c}10 \\
130^{*} \\
12 \\
8\end{array}$ \\
\hline $\begin{array}{l}\text { Total } \\
\text { Recent Stud }\end{array}$ & & 106 & $\begin{array}{l}\text { ract } v \\
\text { Yes }\end{array}$ & $\begin{array}{l}\text { Grst seen } \\
\text { Removed } \\
\text { already }\end{array}$ & $150^{*}$ \\
\hline $\begin{array}{l}\text { Cataract } \\
\text { at final } \\
\text { follow up }\end{array}$ & $\begin{array}{l}\text { Removed before } \\
\text { trabeculectomy } \\
\text { No change } \\
\text { Worse } \\
\text { Worse, requiring } \\
\text { surgery }\end{array}$ & $\begin{array}{l}58 \\
13\end{array}$ & $\begin{array}{l}5 \\
9\end{array}$ & $\begin{array}{l}2 \\
0 \\
0\end{array}$ & $\begin{array}{r}2 \\
63 \\
22\end{array}$ \\
\hline Total & & 72 & 15 & 2 & 89 \\
\hline
\end{tabular}




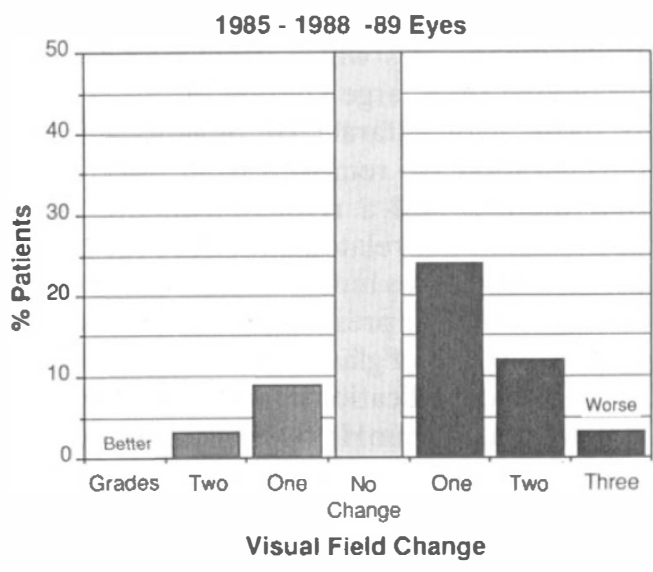

Fig. 7 The changes in the visual field in the follow up of the recent study ( 89 eyes) following trabeculectomy.

val. The presence of cataract prior to trabeculectomy was the strongest determinant of increase in cataract: 7\% (8 of 106 eyes) in those with no preoperative cataract compared to $35 \%$ ( 12 of 34 eyes) in those with a preoperative cataract showed a long term increase in cataract $(\mathrm{p}<0.0001)$. Conversely, of those 20 eyes with an increase in cataract, 12 or $60 \%$ had a previous history of cataract. Twentytwo persons with a cataract when first seen had no increase at final follow up (Table V).

Cataract was not related to the height of intraocular pressure preoperatively, the amount of fall of intraocular pressure after operation, operative complications other than corneal touch, the type or frequency of application of pre operative medications or the type of glaucoma.

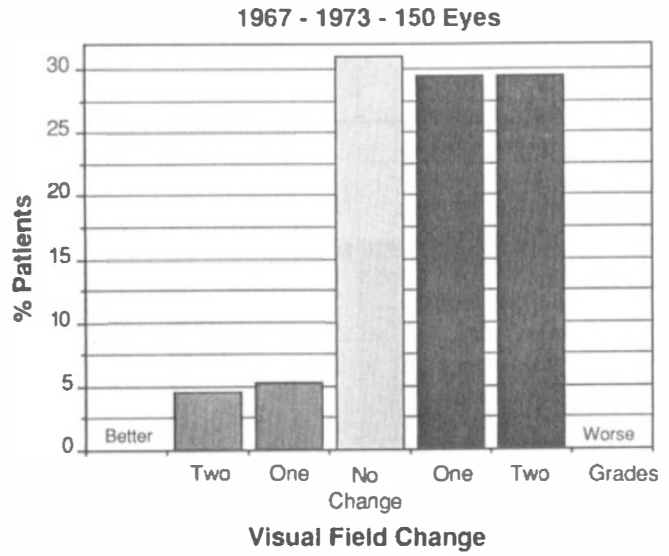

Fig. 8 The changes in the visual field in the follow up of the early study (150 eyes) following trabeculectomy.
A detailed study of the 20 eyes which developed cataract showed no common factor. One patient had diabetes which developed after the operation and four of the patients who had the operation during 1967 had previously been on Eserine (Physostigmine) eyedrops.

\section{Change in Visual Field}

A progressive field change was noted in $59 \%$ of eyes over the duration of the long term follow up in spite of "normalisation" of IOP. Visual field changes were analysed and classified to indicate large major changes only ${ }^{16}$ (Table VI). These changes were less marked in the short term study but even here $38 \%$, showed some change in the follow up period (10\% improving, $28 \%$ getting worse) (Figs. 7, $8,9)$. The field loss and reduction in visual acuity appear to be related (Tables VII, VIII). Rapid reduction in the visual field following surgery was found in 12 eyes; of those three had shallow anterior chambers post operatively, seven had uveitis and two had hyphaemata. However only one patient lost all central vision and this was a late event not immediately related to the surgery which was uncomplicated.

The change in visual field could not be related to the disc appearances which did not change significantly from the immediate post operative reading to the final follow-up, nor could they be related to the height of preoperative intraocular pressure, the amount of fall of intraocular pressure, operative complications of any type, the amount and type of preoperative medication, or the size of the preoperative visual field.

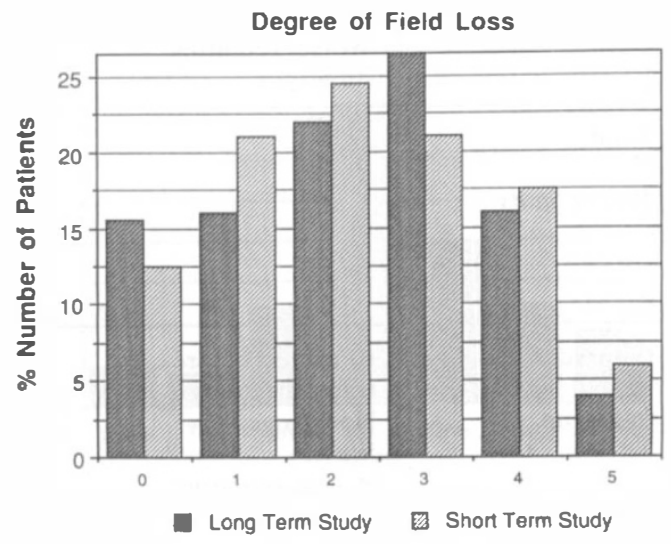

Fig. 9 The degree of field loss noted in each of the studies at presentation using the grading in Table VI. 
Table VI Grading of Visual Field Loss

Grade 1 Early relative or absolute field defects (equivalent to 1-4 Goldmann) of any type but outside $10^{\circ}$ in all quadrants

Grade 2 Absolute field defects within $10^{\circ}$ in one quadrant

Grade 3 Absolute field defects within $5^{\circ}$ in one quadrant

Grade 4 Absolute field defects within $5^{\circ}$ in two or more quadrants

Grade 5 Absolute field defects within $2^{\circ}$ in any quadrant

\section{Preoperative medication}

The amount and type of preoperative medications did not seem to have any effect on the outcome of trabeculectomy. The only factor noted was that of those who developed cataract some had used Physostigmine preoperatively to control the intraocular pressure (Fig. 10).

\section{Preoperative Ocular inflammatory disease}

Preoperative ocular inflammatory disease was present in 11 patients (Table II). Apart from the necessity to suppress the post operative inflammation in those with uveitis, the preoperative condition did not affect the outcome of the operation or increase the rate of complications.

\section{Discussion}

Trabeculectomy was introduced in order to reduce the complications from the operations performed at that time. In this it has been largely successful. Trabeculectomy, as this series confirms, predictably reduces the intraocular pressure to within the normally accepted limits; the higher the preoperative intraocular pressure the greater the fall. Long term follow up over 20 years shows no tendency for trabeculectomy to fail once drainage is established. Results in the short term were almost the same as 20 years later. Both long and short term follow up shows that the initial height of the intraocular pressure or the amount by which it falls does not have any effect either on the production of cataract, reduction of visual field or visual acuity. This study does not support the reports that the intraocular pressure must be reduced below $16 \mathrm{mmHg}$ to retain the visual field (Table VII and VIII). Also comparison of the two groups found that the type and frequency of previous medication had no effect on the outcome of the operation.

The two groups of patients were found to be comparable and the results were also comparable to those already reported. ${ }^{3,6}$ Analysis of the disc and field changes at presentation of the patients who came to the eye department 20 years ago and those who came recently showed no difference between them (Fig. 9); this is in spite of much earlier referral by those in the refracting service who have detected a raised intraocular pressure. It must be concluded that the ability to detect the early stages of glaucoma is just as bad now as it was 20 years ago.

Minor complications at or immediately after surgery such as hyphaema or mild uveitis had no effect on the outcome nor had they any influence on visual acuity, cataract formation or the visual field. A shallow anterior chamber post operatively whether associated with choroidal detachments or not, did not produce any long term ill effects provided there was no contact between the lens and the cornea. Yamishita ${ }^{23}$ has found in a prospective study using Healon in the anterior chamber at the time of surgery that shallow anterior chamber and choroidal detachments can be reduced on the first day post operatively from $25 \%$ to $2 \%$, but the rate of $10 \%$ is the same by the third day. It would seem worth considering the use of Healon if it is felt that the AC might become flat (eg the second eye of pre-

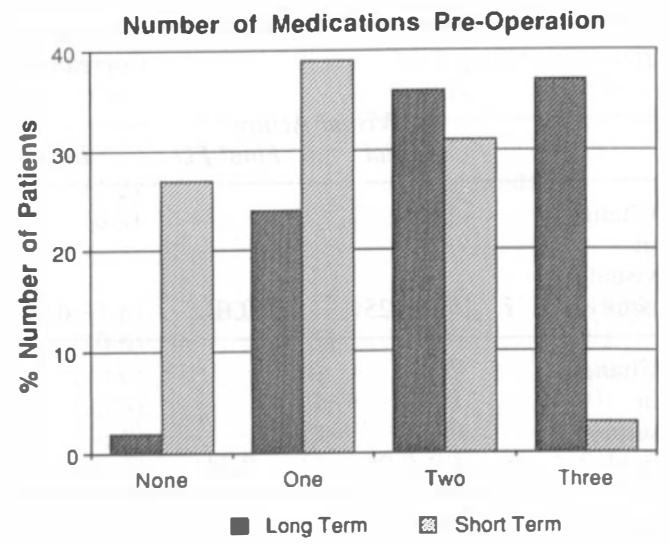

Fig. 10 The number of different medications used preoperatively in the two studies showing the move towards early surgical intervention. 
Table VII Change in Visual Acuity vs Change in Visual Field at Final Follow up

\begin{tabular}{|c|c|c|c|c|c|c|}
\hline \multirow[t]{2}{*}{$A$} & \multicolumn{5}{|c|}{$\begin{array}{l}\text { Crosstabulation of persons } \\
\text { Vorsening of visual field from baseline by grades }\end{array}$} & \multirow[b]{2}{*}{+3 or more } \\
\hline & & -1 or less & 0 & +1 & +2 & \\
\hline $\begin{array}{l}\text { Worsening } \\
\text { of } \\
\text { visual } \\
\text { acuity } \\
\text { from } \\
\text { baseline } \\
\text { by level }\end{array}$ & $\begin{array}{l}-1 \text { or less } \\
0 \\
+1 \\
+2 \\
+3 \text { or more }\end{array}$ & $\begin{array}{l}4 \\
2 \\
3 \\
1 \\
1\end{array}$ & $\begin{array}{r}16 \\
5 \\
10 \\
3 \\
7\end{array}$ & $\begin{array}{l}9 \\
4 \\
5 \\
7 \\
9\end{array}$ & $\begin{array}{l}0 \\
3 \\
6 \\
6 \\
8\end{array}$ & $\begin{array}{l}1 \\
1 \\
2 \\
2 \\
5\end{array}$ \\
\hline
\end{tabular}

viously complicated surgery) but a lack of long term side effects from shallow anterior chambers would not justify routine use.

Stewart and Shields found that patients in whom there had been contact between cornea and lens post operatively had a higher incidence of complications than those who had no such contact. ${ }^{24}$ Of the six patients known to have lenticulo-corneal contact, two have required cataract extraction and another had a permanent reduction of visual acuity and visual field. It would appear that this complication although rare is potentially very serious.

Hypotony with the formation of choroidal effusion has been sited as a major cause of postoperative problems. ${ }^{15}$ Five patients had persistently low pressures of $5 \mathrm{mmHg}$ or less but none developed persistent choroidal detachments. Lamping et $a l^{15}$ found that between $13 \%$ and $17 \%$ of these patients required choroidal 'tap' post operatively. Only five patients $(2 \%)$ in our series required this procedure. This probably reflects the differences in glaucoma populations in different units. This may also be why patients of Lamping et al also showed the significant long term failure rate from trabeculectomy which was not apparent in our investigation. Certainly we could find no patients in our population who would have benefited more by full thickness surgery rather than partial thickness trabeculectomy.

Vitreous and subchoroidal haemorrhages $^{25-28}$, Uveal effusions, ${ }^{29}$ staphyloma and ciliary body incarceration ${ }^{30,31}$ were not observed in those patients analysed for this series.

Table VIII Changes in visual field and visual acuity during the period of follow up 1967 to 1973

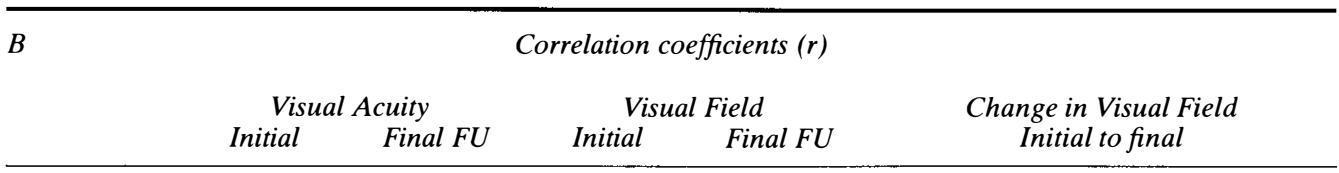

$\begin{aligned} & \text { Change } \\ & \text { in } \\ & \text { visual } \\ & \text { acuity }\end{aligned}$
$\begin{aligned} & \text { Change } \\ & \text { C }\end{aligned}$

significance $\dagger \mathrm{p}<0.01$

$$
\ddagger \mathrm{p}<0.001
$$

$r=$ correlation coefficient of change in the initial visual acuity and visual field against the final visual acuity and visual field.

An increasing number indicates a worsening of the acuity or field. 




Fig. 11 The disc grading noted at presentation in both series, indicating that even with earlier detection of raised Intraocular pressure serious changes have already taken place at presentation.

As with all surgical operations on an open eye there is always the risk of infection, to which is added in all filtering procedures a thin vulnerable conjunctival bleb. It is therefore surprising that infection did not occur in this series and that it appears to be a rare complication overall. Katz et $a l^{33}$ reviewed 1100 trabeculectomies and found only one immediate post operative infection and five late post operative infections which occurred some five to nine years after surgery.

Bleb failure which is most likely to occur immediately after surgery as a result of fibro- sis of the episcleral and conjunctival tissue is likely to occur in young and/or pigmented eyes. This only occurred in $2 \%$ of the patients in this series as opposed to the $13 \%$ reported by Richter et al. ${ }^{34}$ This possibly reflects the differences in the population served in the two series and by the amount of preoperative medication given. It was noted that the inability to detect a bleb in this series was not equated with failure to control the intraocular pressure.

The most important finding in this investigation was that whilst some patients have some improvement of vision and field, a long term reduction in visual acuity and visual fields occurred in over half the patients (Figs 7,8 ). Even if those with increasing cataract, and overt maculopathy are removed from the calculations there is still a reduction in acuity and field of at least two grades or more in $30 \%$ of patients. In spite of detailed analysis of the possible causative factors, the reason for reduction of field is not clear but is not related to the height of the original intraocular pressure, the amount of fall of intraocular pressure induced by operation, the type of glaucoma for which trabeculectomy was performed or whether the preoperative field was small or large, nor is it related to any post operative or long term complication, or to any specific preoperative medication. It would appear therefore that field loss and the related visual acuity undergoes progressive change in

Table IX Visual field change and intraocular pressure at follow up

\begin{tabular}{|c|c|c|c|c|c|}
\hline \multirow[b]{3}{*}{ Intermediate Follow up } & \multicolumn{2}{|c|}{$\begin{array}{c}1967-1973 \\
\text { Visual field worse } \\
\text { by } 2 \text { grades or more }\end{array}$} & & \multicolumn{2}{|c|}{$\begin{array}{c}1985-1988 \\
\text { Visual field worse } \\
\text { by } 2 \text { grades or more }\end{array}$} \\
\hline & $\mathrm{n} / \mathrm{N}$ & $\%$ & & $\mathrm{n} / \mathrm{N}$ & $\%$ \\
\hline & & & & \multirow{4}{*}{\multicolumn{2}{|c|}{ no data }} \\
\hline IOP $<16$ & $2 / 48$ & $(4.2)$ & & & \\
\hline$>16$ & $3 / 47$ & $(6.4)$ & & & \\
\hline & $\mathrm{p}=0.56$ & & & & \\
\hline \multicolumn{6}{|c|}{ Final Follow up } \\
\hline IOP $<14$ & $12 / 38$ & $(31.6)$ & IOP $<14$ & $6 / 41$ & $(14.6)$ \\
\hline 15 & $3 / 10$ & $(30.0)$ & 15 & $0 / 6$ & (0) \\
\hline 16 & $4 / 10$ & $(40.0)$ & 16 & $1 / 9$ & $(10.0)$ \\
\hline 17 & $3 / 9$ & $(33.3)$ & 17 & $0 / 1$ & (0) \\
\hline 18 & $7 / 19$ & $(36.8)$ & 18 & $3 / 9$ & $(33.3)$ \\
\hline 19 & $1 / 10$ & $(10.0)$ & 19 & $0 / 1$ & (0) \\
\hline 20 & $2 / 7$ & $(28.6)$ & 20 & $2 / 7$ & $(28.6)$ \\
\hline $21+$ & $2 / 11$ & $(18.2)$ & $21+$ & $0 / 5$ & $(0)$ \\
\hline & $\mathrm{p}=0.82$ & & & $\mathrm{p}=0.42$ & \\
\hline IOP $<16$ & $19 / 58$ & $(32.8)$ & $<16$ & $7 / 57$ & $(12.3)$ \\
\hline$>16$ & $15 / 56$ & (26.8) & $>16$ & $5 / 27$ & (18.5) \\
\hline
\end{tabular}


Table $\mathbf{X}$ Visual field change and intraocular pressure at follow up

\begin{tabular}{|c|c|c|c|c|}
\hline & $\begin{array}{l}1967-1973 \\
\text { Visual field worse } \\
\text { by } 1 \text { grade or more } \\
\text { n/N }\end{array}$ & $\%$ & $\begin{array}{l}1985-1988 \\
\text { Visual field worse } \\
\text { by } 1 \text { grade or more } \\
\mathrm{n} / \mathrm{N}\end{array}$ & $\%$ \\
\hline \multicolumn{5}{|c|}{ Final Follow up } \\
\hline IOP $<19$ & $58 / 96$ & 60 & $28 / 32$ & 41 \\
\hline \multirow[t]{2}{*}{ IOP > 19} & $9 / 18$ & 50 & $4 / 16$ & 25 \\
\hline & $p=0.41$ & & $p=0.23$ & \\
\hline IOP $<16$ & $38 / 58$ & 66 & $23 / 57$ & 40 \\
\hline \multirow[t]{2}{*}{ IOP $>16$} & $29 / 56$ & 52 & $9 / 27$ & 33 \\
\hline & $\mathrm{p}=0.71$ & & $\mathrm{p}=0.53$ & \\
\hline
\end{tabular}

glaucoma and that the reduction of intraocular pressure alters the rate of this progress but nothing more (Tables VI, VII, VIII, IX). Unfortunately as others who have investigated this phenomena have noted ${ }^{35,36}$ we have found no way of predicting who will have improvement or progressive change and who will not. Although we have seen sudden loss of vision ${ }^{37}$ following trabeculectomy it did not occur in any patient in this series.

It has been suggested that if the intraocular pressure can be reduced to $16 \mathrm{mmHg}$ or less the rate of field loss will be decreased. While in the short term series as well as the intermediate visit of the long term follow up series, there is a slightly greater proportion with worse visual field change in the high IOP category, differences are not large nor significant (Table VII). For the long term follow up there also appears to be no consistent relationship whatever cut off point is used for IOP, nor was there any correlation between IOP and change in field as continuous variables. The difference in this series and others may be in the grading of visual field loss. This series was deliberately weighted to include very severe field loss to determine how often the 'wipe out' of the visual field occurred so that a change of two grades or more indicates a very serious loss of field. However even when the results are analysed for one grade of field loss there is still no trend towards improved retention of field for lower intraocular pressure levels (Table IX).

In this study, development of cataract was not related to the height of the IOP preoperatively, the fall in IOP induced by surgery, the preoperative medications or operative or post operative complications. Cataract increased mainly in those in whom cataract was present preoperatively. Though cataract developed in the long term in some $7 \%$ of the subjects with no preoperative cataracts, cataract is a disease of old age, as is open angle glaucoma, and the two conditions must obviously coexist. Though no population data are available for incidence of cataract, this figure might be thought comparable with expectation in older age groups. There is no evidence from this study that trabeculectomy itself causes cataract (Table V).

Some limitations are apparent in this study. We did not have complete long term follow up on all subjects. Our estimates of the percentage with cataract, visual field, or visual acuity loss on follow up could thus be biased, probably in the direction of adverse outcome since it is possible that those with problems are more likely to return to the clinic, and also to have more visual measurements, and hence, have complete follow up data. However, while this incomplete follow up may bias the absolute percentage figures of those with long term visual loss following surgery, it should not affect the internal comparisons of the correlates of visual change within the study cohorts. As indicated earlier, standardised objective measures for cataract, for example, were not available and we have had to rely on clinical assessment. Also because of the small numbers who have developed cataract we possibly lack the power to detect significant differences. For visual acuity and fields, more objective measures were available. However, unit changes in visual field grades or visual acuity levels cannot be assumed to be of equal magnitudes; for example, loss of field between grades 4 and 5 are probably of much 
greater clinical or pathological severity and significance than between grades 1 and 2 . We analysed differences in visual field grade levels and visual acuity levels quantitatively simply as a means of trying to standardise measures to compare and examine changes in visual field and acuity in subjects who had differing visual baseline status.

The contention that trabeculectomy is a procedure which is relatively free of complications has been sustained in this follow up study, which is as long as trabeculectomy has been performed. However it is quite clear that reduction of the intraocular pressure even early in the disease to a 'normal' level does not prevent a progressive and gradual reduction in both visual acuity and visual field. This change is presumably the result of progressive loss of nerve fibres, as no easily detectable change in the discs of these patients occurred during the prolonged period of follow up. This remains the puzzle in the disease of glaucoma.

\section{References}

${ }^{1}$ Cairns JE: Trabeculectomy Preliminary report. $A m$ J Ophthalmol 1968, 66: 673.

${ }^{2}$ Watson PG: Trabeculectomy. A Modified Ab. Externo Technique. Ann Ophthalmol 1970, 2: 199.

${ }^{3}$ Watson PG and Barnett F: Effectiveness of Trabeculectomy in Glaucoma. Am J Ophthalmol 1975, 79: 831-45.

${ }^{4}$ D'Ermo F, Bonomi L, Doro D: A Critical Analysis of the Long Term Results of Trabeculectomy. Am J Ophthalmol 1979, 88: 829-35.

${ }^{5}$ Marion JR and Shields MB: Thermal Sclerostomy and Posterior Lip Sclerectomy: A Comparative Study. Ophthalmic Surg 1978, 9(6): 67-75.

${ }^{6}$ Watson PG and Grierson I: The Place of Trabeculectomy in the Treatment of Glaucoma. Ophthalmology 1981, 88: 175-96.

${ }^{7}$ Jerndal $T$ and Lundstrom M: 330 Trabeculectomies-A Follow-up Study through 1/2-3 Years. Acta Ophthalmol 1977, 55: 52-62.

${ }^{8}$ Mills KB: Trabeculectomy: A Retrospective Longterm Follow-up of 44 Cases. Br J Ophthalmol 1981, 65: 790-5.

${ }^{9}$ Freedman J, Shen E, Ahrens M: Trabeculectomy in a Black American Glaucoma Population. Br J Ophthalmol 1976, 60: 573-4.

${ }^{10}$ Watkins PH Jr and Brubaker RF: Comparison of Partial-thickness and Full Thickness Filtration Procedures in Open-angle Glaucoma. Am J Ophthalmol 1978, 86: 756-61.

${ }^{11}$ Spaeth GL: A Prospective, Controlled Study to Compare the Scheie Procedure with Watson's Trabeculectomy. Ophthalmic Surg 1980, 11: 498-505.
${ }^{12}$ Shields MB: Trabeculectomy Vs Full-thickness Filtering Operation for Control of Glaucoma. Ophthalmic Surg 1980, 11: 498-505

${ }^{13}$ Blondeau P and Phelps CD: Trabeculectomy Vs Thermosclerostomy: A Randomised Prospective Clinical Trial. Arch Ophthalmol 1981, 99: 810-16.

${ }^{14}$ Lewis RA and Phelps CD: Trabeculectomy Vs Thermosclerostomy: A Five-Year Follow-up. Arch Ophthalmol 1984: 102: 533-6.

${ }^{15}$ Lamping KA, Bellows R, Hutchinson BT and Afran SI: Long-term Evaluation of Initial Filtration Surgery. Ophthalmology 1986, 93: 91-101.

${ }^{16}$ Jay JL and Murray SB: Early Trabeculectomy versus Conventional Management in Primary Open Angle Glaucoma. Br J Ophthalmol 1988, 12: 881-9.

${ }^{17}$ Gressel MG, Heuer DK, Parrish RK: Trabeculectomy in Young Patients. Ophthalmology 1984, 91: 1242-5.

${ }^{18}$ Thommy CP and Bhar IS: Trabeculectomy in Nigerian Patients with Open-Angle Glaucoma. Br J Ophthalmol 1979, 63: 636-42.

${ }^{19}$ Adala HS and Klauss V: Causes of Failure of Trabeculectomy (TET) among Kenyan Africans. East African Med J 1984, 61: 246-53.

${ }^{20}$ Wade A and Banla M: Resultats tonometriques a long term de la Trabeculectomie chez le Noir Africain. J Fr Ophthalmol 1987, 10: 575-7.

${ }^{21}$ Shingleton BJ, Distler JA, Baker BH: Filtration Surgery in Black Patients: Early Results in a West Indian Population. Ophthalmic Surg 1987, 18: 195-9.

${ }^{22}$ Heuer DK et al: Trabeculectomy in Aphakic Eyes. Ophthalmology 1984, 91: 1045-51.

${ }^{23}$ Yamishita $\mathrm{H}$ et al: Trabeculectomy: A prospective Study of Complications and Results of LongTerm Follow-up. Jpn J Ophthalmol 1985, 29: 250-62.

${ }^{24}$ Stewart WC and Shields MB: Management of Anterior Chamber Depth after Trabeculectomy. Am J Ophthalmol 1988, 106: 41-44.

${ }^{25}$ Frenkel REP and Shin DH: Prevention and Management of Delayed Suprachoroidal Haemorrhage after Filtration Surgery. Arch Ophthalmol 1986, 104: 1459-63.

${ }^{26}$ Burney E, Quigley HA, Robin AL: Hypotony and Choroidal Detachment as Late Complications of Trabeculectomy. Am J Ophthalmol 1987, 103: 685-8.

${ }^{27}$ Givens K and Shields MB: Suprachoroidal Haemorrhage after Glaucoma Filtering Surgery. Am J Ophthalmol 1987, 103: 689-94.

${ }^{28}$ Berke SJ et al: Chronic and Recurrent Choroidal Detachment after Glaucoma Filtering Surgery. Ophthalmology 1987, 94: 154-62.

${ }^{29}$ Turut P, Madelain J, Milazzo S: Syndrome D'effusion Uveale apres Trabeculectomie dans un Cas de Sturge-Weber-Krabbe. Bull Soc Opht France 1985, 1: 33-9.

${ }^{30}$ Spaeth GL and Rodrigues MM: Staphyloma as a Late Complication of Trabeculectomy. Ophthalmic Surg 1977, 8: 81-5.

${ }^{31}$ Saari KM and Heikkila LA: Early Post-Operative Pressure rise with Ciliary Body Incarceration into 
Watson Type Trabeculectomy Fistula. Acta Ophthalmol 1987, 65: 30-3.

${ }^{32}$ Segrest DR and Ellis PP: Iris Incarceration Associated with Digital Ocular Massage. Ophthalmic Surg 1981, 12: 349-51.

${ }^{33}$ Katz LJ, Cantor LB, Spaeth GL: Early and Late Bacterial Endophthalmitis following Glaucoma Filtering Surgery. Ophthalmology 1985, 92: 959-63.

${ }^{34}$ Richter CU et al: The Development of Encapsulated Filtering Blebs. J Am Acad Ophthalmol 1988, 95: 1163-8.
${ }^{35}$ Spaeth GL: The Effect of Change in Intraocular Pressure on the Natural History of Glaucoma: Lowering Intraocular Pressure in Glaucoma can result in Improvement of Visual Fields. Trans Ophthalmol Soc UK 1985, 104: 256-64.

${ }^{36} \mathrm{Kidd} \mathrm{MN}$ and O'Connor M: Progression of Field Loss after Trabeculectomy: A Five-Year Follow-up. Br J Ophthalmol 1985, 69: 827-31.

${ }^{37}$ Aggarwal SP and Hendeles S: Risk of Sudden Visual Loss Following Trabeculectomy in Advanced Primary Open-angle Glaucoma. Br J Ophthalmol 1986, 70: 97-9. 